\title{
Challenges in supporting the creation of data minable regulatory codes: a literature review
}

\author{
Krzysztof Wnuk \\ Department of Computer Science \\ Lund University \\ Lund, Sweden \\ Krzysztof.Wnuk@cs.lth.se \\ Brian Berenbach \\ Siemens Corporate Research Inc. \\ Princeton, USA \\ Brian.Berenbach@siemens.com
}

Copyright @ 2011 by Krzysztof Wnuk and Brian Berenbach. Published and used by INCOSE with permission

\begin{abstract}
As standards and regulatory codes are issued by third party organizations and committees, the project organization can neither control the content of all standards that the projects should adhere to, nor negotiate or make changes to them that can make the project development easier. Moreover, large infrastructure projects require compliance with hundreds of standards of regulations coming from different agencies, with different styles and structures. A new approach is needed, one that results in well written, easily mined standard and codes. In this paper, we report on findings from an exhaustive literature survey that reveals that the area of supporting drafting of regulatory codes for the purpose of making them more data minable has not yet been explored.
\end{abstract}

\section{Introduction}

Requirements Engineering (RE) is a cornerstone of effective systems engineering [4]. Requirements traceability, as an integral part of RE, helps to determine that requirements have been mapped to corresponding design components which are later implemented and tested in the executable system [21]. Implementing traceability is not only advised as a good practice in managing projects [65], but also required as a standard component of Software Requirements Specifications for IEEE 830-1998 standard [1]. As the size and complexity of software and system engineering projects continue to grow, the task of establishing and maintaining traceability links can easily become overwhelming and exhaustively time consuming, mainly due to the complexity of potential links between the artifacts [2]. Traceability is also used to provide the evidence of compliance with various regulations, regulatory codes and standards. As standards and regulatory codes are issued by third party organizations and committees, the project organization can neither control the content of all standards that the projects should adhere to, nor negotiate or make changes to them that can make the project development easier. Moreover, large infrastructure projects require compliance with hundreds of standards of regulations coming from different agencies, with different styles and structures, in some cases exceeding 1000 pages per a single regulatory code [6]. Regulatory requirements contribute into the challenging growth of complexity in the system engineering automotive development [56]. Fricke and Schultz [32] mention that system development is facing rapidly changing environments in markets, competition, technology, regulatory and societal systems. Browning points out that the better the market and regulatory environment are understood the more likely the organization can concisely write and correctly interpret stable product requirements [18]. 
Jain et al. mention standard and regulatory requirements in their systems integration process model [39]. Godau points out changing regulatory and political requirements as part of the issue of complexity [35]. Finally, Valeri and Davidz list legal requirements as one of the challenges and opportunities of a new frontier in empirical research in systems engineering [102].

In this paper, we take our previous research efforts [6] as a starting point towards exploring a new approach to tackle the problem of tracing regulatory codes and standards in large industrial projects. The approach that we consider in this work is focusing on providing guidelines for writing standards and regulatory codes that can be later made data minable in an efficient manner. In this paper, we report findings from an exhaustive literature survey that reveals that this area of research has not yet been explored. The goal of the literature survey is twofold:

- $\quad$ Search for reported evidence in studies about traceability between various types of requirements and regulations, codes and legal documents.

- $\quad$ Search for reported evidence in studies about providing unified models and standards for writing regulatory codes and legal documents that can be more easily searched and data mined.

We have used a hybrid method for conducting literature surveys where we combined experts' knowledge and recommendations with both querying scientific databases and manually reading abstracts of the most related conferences proceedings and journals.

\section{Related Work}

Several studies have been published up-to-date about methods and tools for supporting requirements traceability task. Heyens et al. proposes a tool that utilizes the Vector Space Model for information retrieval to automatically retrieve traceability links [36] or trace requirements to defect reports. Cleland-Huang et al. [20] proposed a method of traceability based upon event-notification, or proposed a tool that utilizes probabilistic network model to generate traces between requirements, design elements, code and other artifacts [22][23][55]. Natt och Dag et al. proposed a method and a tool for supporting requirements consolidation activity that uses Vector Space Model (VSM) while finding candidate requirements links [62]. De Lucia et al. proposed a traceability recovery tool based on the Latent Semantic Indexing (LSI) approach to information retrieval [25] which has been tested on students' projects. Finally, Cleland-Huang et al. describe nine best practices for implementing effective automated traceability [21].

In the systems engineering forum, Smartt and Ferreira examines existing research that may guide systems engineering in support of bid and proposal pursuits [73] . Sage and Lynch present an overview of systems integration at all levels of system engineering and management but not in a form of a literature review [68]. Valerdi and Davidz outlined challenges and opportunities in empirical research in systems engineering mentioning the issue of common definition of systems engineering among the accepted standards [102]. Vanek et al. review the systems engineering literature from the metrics and applications in product development perspectives [103]. With respect to literature surveys in software engineering the dominating methodology has currently become the systematic review [45]. Several systematic reviews have been reported in the field of requirements engineering that focus on the elicitation related topics [24][28], cost estimation [40][46], managing quality requirements [79], software engineering in a global context [74] or comparing waterfall and iterative project models [61]. The approach has become so popular that even a systematic review of systematic review has been published [47]. We have found only one systematic review that was focusing on traceability [81]. 


\section{Research methodology}

The literature survey has been conducted using a hybrid approach where we combined three methods for searching the literature: (1) experts' opinion, (2) database searching and (3) reading titles and abstracts. Albeit the systematic literature review methodology has recently been the dominant search methodology utilized by researcher in software engineering and requirements engineering field [47], we have decided to conduct our literature study using another methodology. The reasons why we did not use the systematic review methodology are twofold: (1) it requires an extensive effort to be conducted [78] and (2) it requires a high accuracy search string in order to query scientific databases which in our case was not possible due to lack of complete knowledge about the terminology that should be used in our search. As pointed out by Staples and Niazi [78], the research question has be to clearly defined and narrowed in order to reduce overall effort, and to improve selection and data extraction. Moreover, since we assume that the area of research we will look for is not established the main goal is to explore this area rather than to summarize the current state of the art. Thus, we decided to use multiple methods to search scientific literature, including both bottom up and top down methodologies. The study has been divided into four phases, depicted in Figure 1 and described in the subsections that follow.

Phase 1 - pre-study review. In the first phase of the study, we conducted a pre-study literature review. The goal of this step was to gain an overview of the terminology in the field of regulations, law and legal requirements as well as find some relevant papers that can serve as a starting point for the survey. Since the requirements engineering field is one that both authors have experience in, it was decided to search for relevant papers and authors in this forum first. Two authors in this area have been particularly active: namely Annie Anton and Travis Breaux. The analysis of their work brought useful insights into which phases and key words should be searched. Several conference, workshop and journal publications of Anton and Breaux et al. have been reviewed in this stage. Moreover, the analysis of references of one of the journal publications written by Anton and Breaux [12] helped to complement the list of terms to look for as well as provided some insights of the state of the research within requirements engineering community.

Among the publications written by Breux, 7 papers have been selected for a full review. In the case of finding papers highly similar, we have chosen journal publications. According to Breaux and Anton the challenge in tracing regulations to requirements is the fact that regulations are distributed across multiple sections of the standard document [14]. The work by Breux analyzed in the pre-study focuses on deriving goals, obligations and requirements from different type of regulation and policy documents. In [12] 120 unique goal statements were extracted from over 100 internet policies using a technique called goal mining. Although the paper provides some interesting facts about the number of cross-references in the analyzed documents as well as the patterns that encode rights and obligations, the method used is fully manual and thus not scalable. In [11] the method for extracting rules and obligations from policies and regulations are extended for acquiring and presenting data access requirements and managing priorities between data access requirements. In [10], a process called semantic parameterization was used to derive semantic models from goals mined from privacy policy documents, probably the same as in [12]. The paper does not consider rewriting regulations, only formalizing them using the logic and modeling framework proposed. In [16] a framework that improves accountability by integrating traceability through the policy and requirements lifecycle has been proposed. Finally, in [15] the process of specifying product requirements to comply with Section 508 of the U. S. Workforce Investment Act (WIA) of 1998 is described. Albeit the paper discuses experiences and challenges in the process of mapping a legal document to requirements, the paper does not discuss the possibly of automating the process of creating regulations and law documents, leaving it fully manual and thus very time consuming 


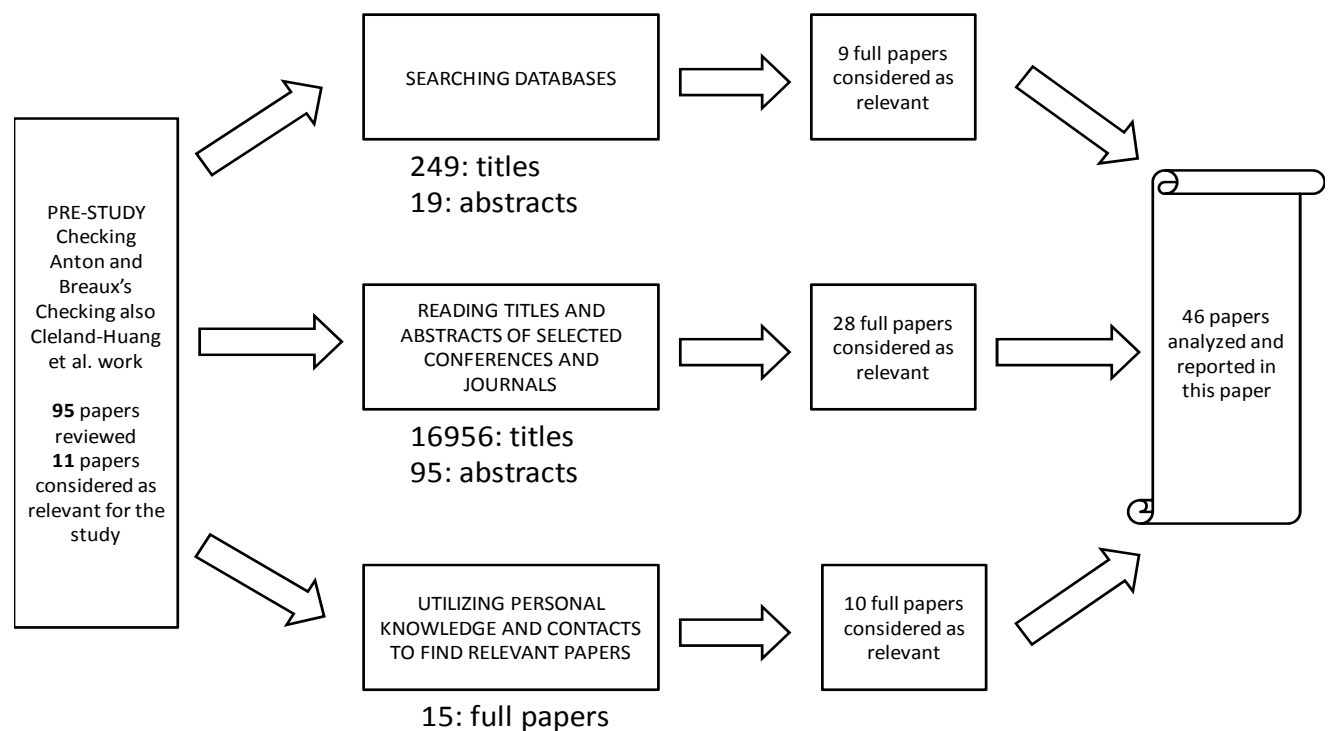

Phase 1

Phase 2

Phase 3

Phase 4

pre study

searching

assessing

reporting

Figure 1 - The outline of the research methodlogy process.

Among the publications that discuss the possibilities of automatic tool support, [16] provides requirements for a tool that can support delegating high-level goals in the organization so that compliance officers and auditors can later evaluate the delegation and refinement decisions made by the personnel. Kiyaviskaya et al. [48] present results from two empirical evaluations of a tool that extracts conceptual models from regulatory texts. Although the tool proposed provides an interesting solution to parsing the input documents using context-free grammars, the transformation rules and annotations are done using an annotation schema constructed beforehand "either automatically or using some learning methods or manual in collaboration with domain experts" [48]. In this case, the construction of the annotation schema has been done manually which implies that the rules are purely heuristics and could have been biased towards the used input data. Moreover, reviewed research effort published by Breux et al. does not consider rewriting or reformulating legal requirements or regulatory codes, they first have to be represented in some kind of logic or other formal description to be then processed and analyzed.

The analysis of work by Anton et al. included over 70 peer-reviewed papers where 3 were selected for full reading and one book chapter was also selected for full reading. The low number of selected papers is because Anton published some work together with Breaux and this work is included in the papers by Breux analyzed in the section above. In [64] the authors survey research efforts over last 50 years in handling legal texts for systems development. Most of the techniques presented in [64] use some kind of logic to model legal texts. Surprisingly, the paper does not report a single study that takes the approach of rewriting legal standards or documents so that the analyses can be automated. In [54] $\mathrm{Li}$ et al. present an interesting relational semantics for Platform for Privacy Preferences (P3P) policies which model the relationships between different components of P3P statements. Based on semantics they propose preference languages that can query the meaning of a privacy policy rather than its syntactic representation. Finally, in [60] an approach to develop production rules, models to aid 
acquiring software requirements from regulatory texts in described. The method is implemented in prolog and exemplified on sections of the HIPAA privacy rule. Additionally, we have reviewed the book chapter by Anton et al. [65] that turned out to be an extension of [64] and also read references on the IEEE Transactions on Software Engineering paper written together with Breaux [11]. The analysis of the reference list in [11], added two potential papers [52][53], where one was from the forum that was not known. Although the topic of the included papers was security requirements, we have decided to include both conferences that the papers originated from to the list of forums which proceedings will be checked in the next phase of the study.

Phase II - Searching for literature. In this phase, several search strategies have been applied for searching relevant papers. For the purpose of this survey, we have utilized three strategies for collecting data: (1) searching scientific databases with a given search strings, (2) reading titles and abstracts for selected conferences and journal and (3) using experts' knowledge, experience and the contact network to find relevant papers. The details of each method and its methodology are described in the subsections that follow.

Searching the databases. We have searched the following databases: (1) Inspec, which indexes IEEE publications, (2) ACM Digital Library, (3), IHS Int'l, (4) Standards \& Specifications, (5) ANSI, (6) Google. The search has been limited to years between 2000 and 2010. Several combinations of the search string including terms related to regulations and standards, traceability and compliance. The details of various search sub-strings with resulting number of titles and abstracts are outlined in Table 1. If the query resulted in more than 50 records only the first 50 were analyzed since the query was sorted by the database engine according to the relevance.

Table 1 - The results of searching selected scientific databases.

\begin{tabular}{|l|l|l|l|}
\hline SEARCH STRING & TITLES & ABSTRACTS & FULL PAPERS \\
\hline “standards” AND “legal requirements” & 35 & 2 & 1 [27] \\
\hline “standards" " AND “meta models” & 50 & 1 & 0 \\
\hline $\begin{array}{l}\text { “traceability” AND (“regulations” OR “codes” } \\
\text { OR “standards”) AND “requirements” }\end{array}$ & 50 & 4 & $1,[58]$ \\
\hline $\begin{array}{l}\text { (“standards” OR “codes” OR “regulations”) } \\
\text { AND “legal requirements” }\end{array}$ & 50 & 5 & $3,[28][48][15]$ \\
\hline $\begin{array}{l}\text { “standards” AND “customer requirements” } \\
\text { AND “compliance” }\end{array}$ & 7 & 1 & 0 \\
\hline “meta-model” AND “compliance” & 50 & 2 & $1,[71]$ \\
\hline
\end{tabular}

Apart from queries the search resulted retrieved 7 individual papers where four ([7] [29] [50][101]) of them were considered as relevant.

Reading titles and abstracts of selected proceedings. Next, we have reviewed proceeding of selected conferences and journals. As the first step, conferences and journals within Requirements Engineering field have been examined. The following series of proceedings have been included in this step:

- International Conference on Requirements Engineering - from 1994 to 2009 [92].

- International Workshop on Requirements Engineering Foundation of Software Quality (REFSQ) - from 1994 to 2009 [94].

- Requirements Engineering Journal - issues and volumes from 1997 to 2010 [97].

- International Workshop on Requirements Engineering and Law (ReLaW) - editions 2008 and 2010 [98].

\footnotetext{
${ }^{1}$ By standards we mean here not only technical standards.
} 
Table 2 - The results of reading titles and abstract of selected conference proceedings and journals in Requirements Engineering field.

\begin{tabular}{|l|l|l|l|}
\hline Proceedings /Journal & Titles & Abstracts & Full Papers \\
\hline RE Conference & 835 & 6 & 5, [12], [104], [15], [17] ,[60] \\
\hline REFSQ & 259 & 6 & 1 [38] \\
\hline RE Journal & 299 & 11 & 3 [2], [37], [59] \\
\hline ReLAW workshop & 24 & 4 & 4, [58], [71], [72], [49] \\
\hline
\end{tabular}

The summary of findings is outlined in Table 2. Next, we have analyzed proceedings of Software Engineering and systems engineering related conferences and journals. We have also selected some related workshops that may contain relevant papers. The summary in terms of number of titles and abstracts analyzed as well as the number of full papers that were analyzed in the next stage are outlined in Table 3 . The following proceedings were analyzed:

- $\quad$ Int. Conference on Software Engineering (ICSE) [82]

- Int. Conference on Machine Learning and Applications (ICMLA) [89]

- $\quad$ Int. Conference on Artificial Intelligence and Law (ICAIL) [90]

- $\quad$ Int. Conference on Global Software Engineering (ICGSE) [83]

- Int. Workshop on Mining Software Repositories at ICSE [91]

- $\quad$ Int. Workshop on Software Engineering in Healthcare at ICSE (SEHC) [86]

- $\quad$ World Congress on Engineering \& Computer Science (WCECS) [87]

- Int. Workshop on Traceability in Emerging Forms of SE at ICSE [84]

- International Workshop on SE for Secure Systems at ICSE [85]

- International Conference on Machine Learning and Computing (ICMLC) [88]

- $\quad$ Transactions on Software Engineering Journal (TSE) [99]

- $\quad$ Empirical Software Engineering Journal (ESEJ) [93]

- $\quad$ Information and Software Technology Journal (IST) [96]

- $\quad$ Software Quality Journal (SQJ) [95]

- $\quad$ Systems Engineering Journal (SEJ)

- $\quad$ Conference on Systems Engineering Research (CSER)

Table 3 Results of reading titles and abstract of selected conference proceedings and journals in Software Engineering field.

\begin{tabular}{|l|l|l|l|}
\hline $\begin{array}{l}\text { CONFEFERENCE } \\
\text { JOURNAL TITLE }\end{array}$ & \# TITLES & \# ABSTRACTS & \# FULL PAPERS \\
\hline ICSE [82] & 1498 & 11 & 1 [22] \\
\hline ICMLA [89] & 564 & 2 & 0 \\
\hline ICAIL [90] & 437 & 21 & 8, [3], [67], [70], [9], [75], [69], [8], [77] \\
\hline ICGSE [83] & 165 & 0 & 0 \\
\hline MSR at ICSE [91] & 131 & 0 & 0 \\
\hline SEHC at ICSE [86] & 27 & 2 & 1 [105] \\
\hline WCECS [87] & 1431 & 2 & 0 \\
\hline TEFSE at ICSE [84] & 33 & 1 & 0 \\
\hline SESS at ICSE [85] & 45 & 3 & 2 [52], [53] \\
\hline ICMLC [88] & 72 & 2 & 0 \\
\hline TSE Journal [99] & 5945 & 8 & 0 \\
\hline ESEJ Journal [93] & 559 & 3 & 0 \\
\hline
\end{tabular}




\begin{tabular}{|l|l|l|l|}
\hline IST Journal [96] & 3587 & 3 & 0 \\
\hline SQJ [95] & 310 & 1 & 0 \\
\hline SEJ [107] & 304 & 3 & 0 \\
\hline CSER [106] & 431 & 3 & $1[6]$ \\
\hline
\end{tabular}

We have also reviewed systems engineering related literature. In particular, we have been interested in the proceedings of the INCOSE Symposium on Systems Engineering, systems Engineering journal and Conference on Systems Engineering Research. Three papers have been identified for full analysis in this phase ([100], [57] and [30]). We have also read titles of all papers published in the Systems Engineering journal proceedings (up to volume 14 issue 1). Out of total 304 titles we have found 3 abstracts and 0 full papers that are relevant to the topic. After reading titles of papers published at the CSER conference (between years 2004 and 2010) we have added 431 titles found 3 abstract potentially interesting and one full paper [6].

Using experts' knowledge and experience to search relevant papers. In the last phase of searching for literature, we used practical knowledge and the contact network of the second author, who is an experienced practitioner in the requirements engineering and system engineering fields. We have also asked two other independent professionals (one Professor in the Software Engineering field and one Professor of Civil and Environmental Engineering) to help with finding related articles. The experts used their contacts network to ask about related publications and review the history of past project and industrial experience to recall related publications. The resulting set of 10 papers added to the analysis set: [5], [6],[7],[19],[31],[33],[41],[42],[43], [51]

\section{Results}

In this section, we present the results of the survey using visualization and methodology of a systematic map approach [66]. To categorize the resulting set of 46 papers, we have used three categories, namely: contribution facet, research facet and topic facet. The first two categories were reused from the paper by Petersen et al. [66] while the third category has been created for the purpose of this study.

In the first category the papers were examined based on the contribution that they provided. The possible values for this category are: (1) metric, (2) tool, (3) model, (4) method or (5) process. The possible values for the research facet category are: (1) evaluation research, (2) validation research, (3) solution proposal, (4) philosophical paper, (5) experience report and (6) opinion paper. The third category has been defined in relation to our research questions and has the following values: (1) regulatory codes creating, (2) regulatory codes tracing, (3) regulatory codes searching and analyzing, (4) law creating, (5) law tracing and (6) law searching and analysis. Papers not explicitly mentioning traceability, but describing similar analysis steps as for establishing traces between the artifacts, were categorized into searching and analyzing. The categorization step has been done by two authors, working independently. The results were compared, discussed and conflicts were resolved during a consolidation meeting. The summary of the categorization is depicted in Figure 2.

Among the evaluation research papers (34.7\% of all papers in category), 6 papers $(13.04 \%$, [75], [69], [77], [104], [15], [58]) were categorized as law searching and analyzing. Four papers in this category $(8.7 \%,[22],[33],[6],[2])$ describe tracing regulatory codes to requirements, while another four (8.7\%, [19], [43], [17], [11]) searching and analyzing regulatory codes. Among experience reports category (15.2\% of all papers), two papers address the creating regulations category ([57], [101]), two others tracing to regulatory codes and three analyzing regulatory codes ([53], [37], [100]). Among opinion papers (6.52 \% of all papers), we have found one paper in the category of analyzing of legal texts ([49]) and two 
papers about creating regulations ([7], [50]). In the philosophical papers category, three papers ([38], [72] and [44]) describes the analysis of law and legal documents (6.32\%), two analyzing regulations ([80], [44] 4.55\%) and one issues related to creating regulations [31]. The second biggest category is the solution papers $(28.2 \%)$. In this case, we categorized one paper as creating regulations [29] six papers as analyzing regulations [105], [52], [41], [51], [58], [30] (13.04\%) and six papers as searching and analyzing law [67], [9], [8], [59], [71], [60]. Finally one paper [12] has been categorized as validation research and describes searching and analyzing law facet.

Among the second category of analysis (visualized on the right side of the $\mathrm{Y}$-axis in Figure 2 as positive values), $41.9 \%$ of all papers (19 papers) describe a method. In this case, 8 papers (17.39 \%) discuss searching and analyzing law documents. 13.64\% (7 papers) discuss searching and analyzing regulatory codes (15.22 \%). The remaining three papers (6.52 \%) [6], [22], [33], describes tracing between requirements and regulatory codes and finally one paper ([50]) falls into the category of creating regulatory codes. Six papers (13\% of all papers) were categorized into the model category, two for creating regulations ([27], [29] ) and one for creating law ([3]). Furthermore three papers describe models for searching and analyzing law documents ([9], [8], [58]). For the papers describing a process (26\% of all papers), four papers [7], [31], [57], [101] describe the process of creating regulatory codes, one paper the process of tracing regulatory codes [5] and four papers the process of searching and analyzing regulatory codes [53], [37], [17] and [100]. Finally, three papers were categorized as searching and analyzing law documents [38], [44] and [49].

Seven papers describe tools (15.2\% of all papers); three of them were categorized as tools for searching and analyzing regulatory codes ([19], [42] and [43]). Two other papers describe tools for searching and analyzing law documents ([67] and [75]). Finally one paper ([2], 2.27\%) describes a tool for tracing regulatory codes while the other paper [70] describes a tool for creating law documents. The last category in this dimension of analysis is the metric category where we categorized two papers. One paper describes metrics for searching and analyzing regulatory codes [30] and one paper describes techniques for searching and analyzing law documents [15].

Challenges and new research areas discovered. Among the papers analyzed in this survey, six papers were categorized in the creating regulations category. Two of them have been categorized as opinion papers [7], [50]. In [50], Lane states that companies should stop creating different standards and start collaboration on common, preferably global standards that will help better satisfy customers' needs and stop “recent format fights”. Moreover, Lane advises companies to review their participation in standards bodies to ensure that their membership contributes to those organizations' best practices. In [7], Best describes the characteristics in terms of similarities and differences between various standards organizations.

Two papers have been categorized into the experience report category [57], [100]. In [100], Updegrove describes the raise of a new type of organization to address the situation of providing a set of tightly coordinated standards for many different standards organizations. This organization should be responsible for assembling standards suites, rather than setting the standards themselves. Thus, the paper operates on a meta-level of standards rather than the individual standards level which may only be partly useful for the purpose of data mining (applicable only for the selection of the input data phase). In the second paper, Mackey [57] describes the regulatory history and environment for development of telecommunications systems in the United States.

Regarding the solution proposal for creating a regulatory codes category, Dori et al. [29] propose a combined, model-based structured graphical and textual meta-standard approach for specification, verification and validation of complex systems in general and ISO enterprise 
standards in particular. The core of the proposed solution is representing requirements for complex systems and in particular standards using a constrained, standard subset of English. This subset of English can be automatically translated into the OPM model representation which is later used for validation and verification. However, the authors do not discuss if and how this representation can improve the results of linguistic algorithms while searching for traceability links between requirements and regulations.

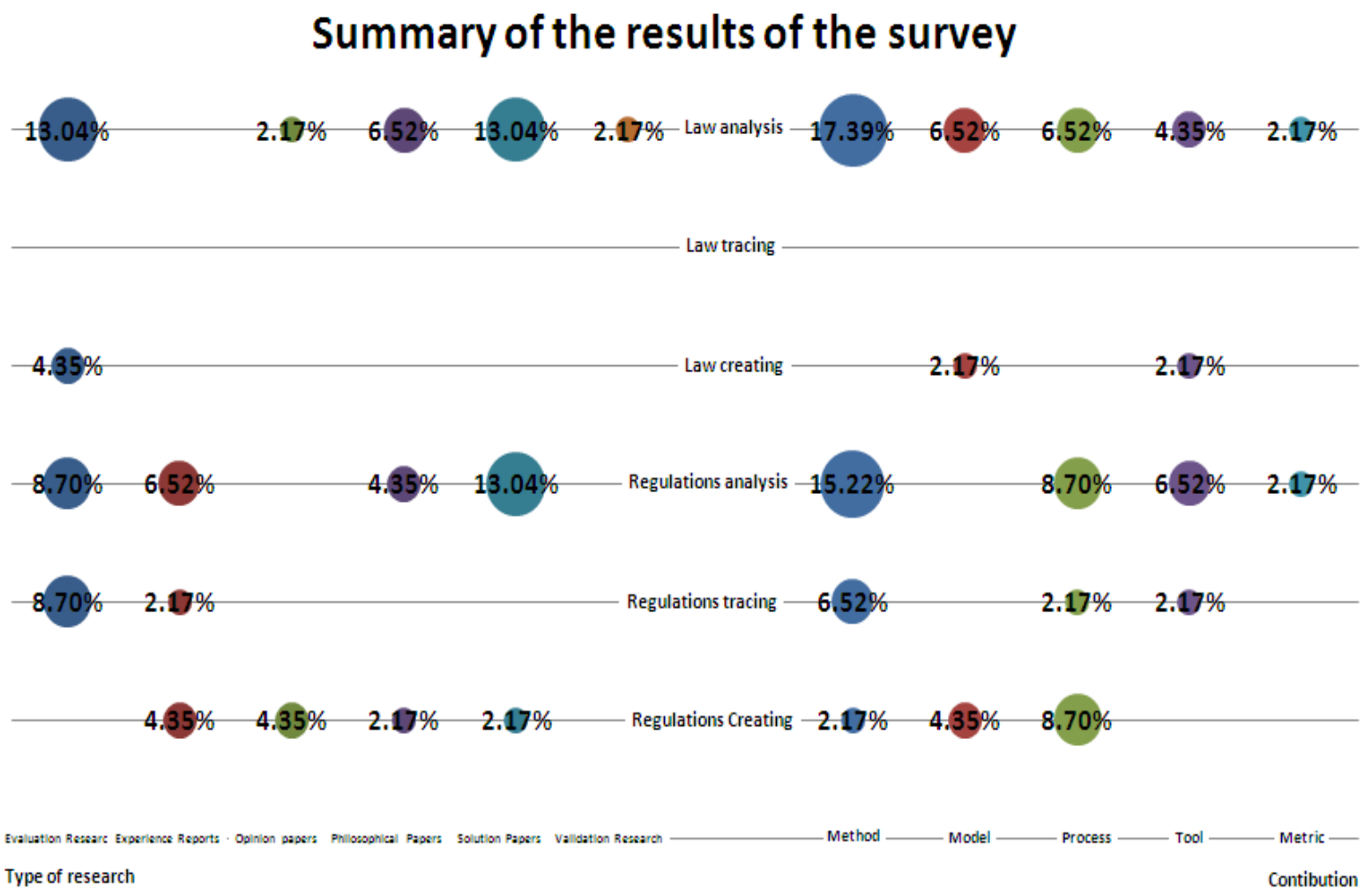

Figure 2 - The summary of the results of the study.

Finally one paper in the creating regulations category turned out to be a philosophical paper where Fenves et al. [31] stress the need for research that addresses the inadequacies of the current representation of standards and creates models that are able to represent all, or almost all, of the different types of provisions in any given standard. A more unified representation should deliver a much richer set of processing functionalities that can better support using design standards in earlier phases of design; support treatment of multiple standards available from distributed sources and determine what type of support is needed from the textual version of a design standard to the formal models which are computable.

Apart from supporting the process of creating regulatory codes, our study revealed a lack of publications that address or support the process of tracing to law documents. Moreover, only two publications were categorized to the law creating category [3], [70]. Bench-Capon [3] presents a study from 1987 that is addressing the provision of knowledge based decision support to large legislation based organization. The particular, organization providing the focus of this project is the UK's Department of Health and Social Security, which is responsible for making and administrating law relating to Social Security benefits. The system provides a formalization of the knowledge required while drafting regulations. PROLOG was used as the modeling language. However, the author did not address or discuss the issue of writing more data minable regulatory documents. In the second paper, Schweighofer et al. [70] present a 
KONTERM system where legal knowledge about concepts and documents is represented by a knowledge base which is structured by statistical and connectionist methods. However, although the results shows that neural methods in combination with statistical methods are a very promising tool for the computation of similarities in large text corpora, it remains an open question whether or not this was of partitioning will be beneficial for automatic methods for supporting traceability.

\section{Conclusions}

Regulatory codes and standards, for the most part, are written today the way they were a century ago. However, the number and variety of regulatory codes impacting large and mega-projects has exploded (e.g. environmental codes). On an infrastructure project recently that one of the authors was involved with, there were over 300 regulatory codes that potentially impacted project activities and deliverables. Complying with the many and varied standards and codes can easily strain the resources of an organization; failing to understand and follow them can result in severe consequences for the organization and the public at large.

A new approach is needed, one that results in well written, easily mined standard and codes. As a corollary, a similar approach is needed at the other end of the tracing structure, e.g. contract and system requirements. For a start, a universal glossary would help, something, for example, such as the North American Industry Classification System. Automated tracing techniques are not industrially viable unless the recall metric exceeds $90 \%$ [21]. With our current knowledge of data mining and text processing, it should be possible through research to come up with, in the near future, techniques for creating standards, regulatory codes, and other project documents for which automatic tracing can completely replace the current onerous and error prone manual techniques.

\section{Acknowledgment}

This work is supported by VINNOVA (Swedish Agency for Innovation Systems) and Siemens Corporate Research Inc. Special thanks to professors: Björn Regnell and Kincho H. Law for their valuable input into the study and to Gabriella DeAngelis for excellent language comments.

\section{References}

[1] IEEE Std 830-1998. Recommended Practice for Software requirements Specification. Last visited, August

2010, http://standards.ieee.org/reading/ieee/std_public/description/se/830-1998_desc.ht $\mathrm{ml}$

[2] Armitage, S, R. Stevens, and A. Finkelstein. 1998. Implementing a compliance manager. Requirements Engineering 3(2): 98-106.

[3] Bench-Capon, T. J. 1987. Support for policy makers: formulating legislation with the aid of logical models. In Proceedings of the 1st international Conference on Artificial intelligence and Law (Boston, USA). pp. 181-189.

[4] Berenbach, B, D Paulish, J. Kazmeier, and A. Rudorfer. 2009. Software \& Systems Requirements Engineering: In Practice. Mc Graw Hill.

[5] Berenbach, B, L-Y. Lo, and B. Sherman B. 2010. Contract-Based Requirements Engineering. Third International Workshop on Requirements Engineering and Law. September 2010. IEEE.

[6] Berenbach, B, D. Grusemann, D. and J. Cleland-Huang. 2010. The Application of Just In Time Tracing to regulatory Codes and Standards. In Proceedings of $8^{\text {th }}$ Conf. on Systems Engineering Research CSER. 
[7] Best, K.F. 2007. Convergence and harmonization of standards organizations. In proceedings of the $5^{\text {th }}$ Int. Conference on Standardization and Innovation in Information Technology. Calgary. pp.105-112,

[8] Biagioli, C, E. Francesconi, A. Passerini, S. Montemagni, and S. Soria, C. 2005. Automatic semantics extraction in law documents. In Proceedings of the 10th international Conference on Artificial intelligence and Law (Bologna, Italy, June 06 - 11, 2005). ICAIL '05. ACM, New York, NY, 133-140.

[9] Branting, L. K, J. C. Lester, and C. B. Callaway. 1997. Automated drafting of self-explaining documents. In Proceedings of the 6th international Conference on Artificial intelligence and Law (Melbourne, Australia, June 30 - July 03, 1997). ICAIL '97. ACM, New York, NY, 72-81.

[10] Breaux, T. D, and A. I. Antón. 2005. Analyzing goal semantics for rights, permissions, and obligations. Proceedings of the 13th IEEE International Conference on Requirements Engineering. Paris. pp. 177- 186.

[11] Breaux, T. D, and A. I. Antón. Analyzing Regulatory Rules for Privacy and Security Requirements, IEEE Transactions on Software Engineering 34 (1): 5-20.

[12] Breaux, T. D. 2009. Exercising Due Diligence in Legal Requirements Acquisition: A Tool-supported, Frame-Based Approach. In proceedings of $17^{\text {th }}$ IEEE Requirements Engineering Conference. Atlanta GA. pp. 225-230.

[13] Breaux, T. D, and A. I. Antón. 2005. Mining rule semantics to understand legislative compliance. In Proceedings of the 2005 ACM Workshop on Privacy in the Electronic Society (Alexandria, VA, USA, November 07 - 07, 2005). WPES '05. ACM, New York, NY, 51-54.

[14] Breaux, T. D, and A. I. Antón. 2007. A Systematic Method for Acquiring Regulatory Requirements A Frame-Based Approach, In Proceedings of the $6^{\text {th }}$ International Workshop on Requirements for High Assurance Systems (RHAS-6), September 2007.

[15] Breaux, T. D, A. I. Antón, K. Boucher, and M. Dorfman. 2008. Legal Requirements, Compliance and Practice: An Industry Case Study in Accessibility. In Proceedings of the $16^{\text {th }}$ IEEE International Requirements Engineering Conference (Barcelona, Spain). pp. 43-52.

[16] Breaux, T. D, A. I. Antón, and E. H. Spafford. 2009. A distributed requirements management framework for legal compliance and accountability. Computers \& Security, vol. 28 (1-2): 8-17.

[17] Breaux, T. D, M. W. Vail, and A. I. Antón. 2006. Towards Regulatory Compliance: Extracting Rights and Obligations to Align Requirements with Regulations. In Proceedings of the 14th IEEE Int. Requirements Engineering Conference (September 11 15, 2006). RE. IEEE Computer Society, Washington, DC, 46-55.

[18] T. R. Browning. 1999. Sources of Schedule Risk in Complex System Development. Systems Engineering 2(1):129-142.

[19] Casson A and D. Stone. 1992. An expertext system for building standards, Vanier D, Russell T (ed.); Computers and information in construction; Montreal, May, Canada.

[20] Cleland-Huang, J, C. K. Chang, and M. Christensen. 2003. Event-Based Traceability for Managing Evolutionary Change. IEEE Transactions of Software Engineering. 29 (9): 796-810.

[21] Cleland-Huang, J, B. Berenbach, S. Clark, R. Settimi and E. Romanova. 2007. Best Practices for Automated Traceability. Computer 40 (6): 27-35. 
[22] Cleland-Huang, J, A. Czauderna, M. Gibiec, and J. Emenecker. 2010. A machine learning approach for tracing regulatory codes to product specific requirements. In Proceedings of the 32nd ACM/IEEE international Conference on Software Engineering - Volume 1. ICSE '10. ACM, New York, NY, 155-164.

[23] Cleland-Huang, J, R. Settimi, C. Duan, and X. Zou 2005. Utilizing supporting evidence to improve dynamic requirements traceability. In Proceedings of the $13^{\text {th }}$ IEEE International Conference on Requirements Engineering. (Paris, France). 135- 144.

[24] Davis, A, O. Dieste, A. Hickey, N. Juristo, and A. M. Moreno. 2006. Effectiveness of Requirements Elicitation Techniques: Empirical Results Derived from a Systematic Review. In Proceedings of the $14^{\text {th }}$ IEEE International Conference on Requirements Engineering. Chicago, IL.

[25] De Lucia, A, G. Fasano, F.Oliveto, and R. Tortora, G. 2005. ADAMS Re-Trace: A Traceability Recovery Tool. In Proceedings of the Ninth European Conference on Software Maintenance and Reengineering (CSMR'05).

[26] De Lucia, A, G. Fasano, F. Oliveto, and R. Tortora, G., 2007. Recovering traceability links in software artifact management systems using information retrieval methods. ACM Trans. Software Engineering and Methodology 16(4):1-50.

[27] Deshpande, R, J. D. Margolis, L. S. Paine, and K. E. Bettcher. 2005. Up to Code: Does Your Company's Conduct Meet World-Class Standards?. Harvard Business Review, December 2005: 122-133.

[28] Dieste, O, and N. Juristo. 2011. Systematic Review and Aggregation of Empirical Studies on Elicitation Techniques. IEEE Transactions on Software Engineering 37(1): 1- 22.

[29] Dori, D, R. Martin, and A. Blekhman. 2010. Model-based meta-standardization. Proceedings of the $4^{\text {th }}$ Annual IEEE Systems Conference. pp.593-597, 5-8 April 2010

[30] Edwards M. 2009. The Impact of Technical Regulation on the Technical Integrity of Complex Engineered Systems. 19th Annual INCOSE International Symposium (INCOSE 2009).

[31] Fenves, S. J, J. H. Garrett, H. Kiliccote, K. H. Law, K. A. Reed. 1995. Computer Representations of Design Standards and Building Codes: U.S. Perspective, International Journal of Construction Information Technology 3(1): 13-34.

[32] Ernst F. and A. P. Schulz. 2005. Design for changeability (DfC): Principles to enable changes in systems throughout their entire lifecycle. Systems Engineering 8(4): 308.1-308.2.

[33] Gibiec, M, A. Czauderna, and J. Cleland-Huang. 2010. Towards mining replacement queries for hard-to-retrieve traces. In Proceedings of the IEEE/ACM international Conference on Automated Software Engineering (Antwerp, Belgium, September 20 - 24, 2010). ASE '10. ACM, New York, NY, 245-254.

[34] Giorgini, P, F. Massacci, J. Mylopoulos, N. Zannone. 2005. Modeling security requirements through ownership, permission and delegation. In Proceedings of the $13^{\text {th }}$ IEEE International Conference on Requirements Engineerin[28]g, Paris France pp. 167176.

[35] R. I. Godau. 1999. The changing face of infrastructure management. Systems Engineering, 2(4): 226-236.

[36] Huffman Hayes, J, A. Dekhtyar, S. Karthikeyan Sundaram, E. A. Holbrook, S. Vadlamudi, and A. April. 2007. REquirements TRacing On target (RETRO): improving software maintenance through traceability recovery. Innovations in Systems and Software Engineering 3(3): 193-202. 
[37] Irvine, C. E, T. Levin, J. D. Wilson, D. Shifflett and B. Pereira. 2002. An approach to security requirements engineering for a high assurance system. Requirements Engineering, 7(4): 192.208.

[38] Islam, S, H. Mouratidis, and S. Wagner. 2010. Towards a Framework to Elicit and Manage Security and Privacy Requirements from Laws and Regulations. Requirements Engineering: Foundation for Software Quality. Lecture Notes in Computer Science 6182: 255-261.

[39] Jain R, A. Chandrasekaran, and O. Erol. 2009. A Systems Integration Framework for Process Analysis and Improvement. Systems Engineering 13(3): 274-289.

[40] Jorgensen, M, and M. Shepperd. 2009. A Systematic Review of Software Development Cost Estimation Studies. IEEE Transactions on Software Engineering 33(1): 33-53.

[41] Kerrigan, S. L. 2003 A Software Infrastructure for Regulatory Information Management and Compliance Assistance. Doctoral Thesis. UMI Order Number: AAI3104258., Stanford University.

[42] Kerrigan, S, C. Heenan, H. Wang, K. H. Law, and G. Wiederhold. 2003. Regulatory information management and compliance assistance. In Proceedings of the 2003 Annual National Conference on Digital Government Research (Boston, MA, May 18 - 21, 2003). ACM International Conference Proceeding Series, vol. 130. Digital Government Society of North America, 1-1.

[43] Kerrigan S. L, and K. H. Law. 2005. A Regulation-Centric, Logic-Based Compliance Assistance Framework. Journal of Computing in Civil Engineering 19(1): 1-15

[44] Kimbrough, S, O. Lee, T. Y. Padmanabhan, B. and Y. Yang. 2003. On original generation of structure in legal documents. In Proceedings of the 9th international conference on Artificial intelligence and law (ICAIL '03). ACM, New York, NY, USA, 152-161.

[45] Kitchenham, B, A. Pfleeger, S. L. Pickard, L. M. Jones, P. W. Hoaglin, D. C. Emam, and J. Rosenberg. 2002. Preliminary guidelines for empirical research in software engineering. IEEE Transactions on Software Engineering 28(8): 721-734.

[46] Kitchenham, B, A. Mendes, and E. Travassos. 2007. Cross versus Within-Company Cost Estimation Studies: A Systematic Review. IEEE Transactions on Software Engineering 33(5): 316-329.

[47] Kitchenham, B, O. Pearl Brereton, D. Budgen, M. Turner, J. Bailey, and S. Linkman. 2009. Systematic literature reviews in software engineering - A systematic literature review. Information and Software Technology 51(1): 7-15.

[48] Kiyavitskaya, N. Zeni, N. Breaux, T. D. Antón, A. I. Cordy, J. R. Mich, and J. Mylopoulos. 2008. Automating the Extraction of Rights and Obligations for Regulatory Compliance. In Proceedings of the 27th international Conference on Conceptual Modeling (Barcelona, Spain, October 20 - 24, 2008). Q. Li, S. Spaccapietra, E. Yu, and A. Olivé, Eds. Lecture Notes In Computer Science, vol. 5231. Springer-Verlag, Berlin, Heidelberg, 154-168.

[49] Kiyavitskaya, N. Krausova, and A. Zannone, N. 2008. Why Eliciting and Managing Legal Requirements Is Hard. Requirements Engineering and Law, 2008. RELAW '08. 26-30, 9 Sept. 2008.

[50] Lane, G. T. 2009. Best Practices for Standards Communities. Computer 42(7): 86-87.

[51] Lau, G. T, S. Kerrigan, H. Wang, K. H. Law, and G. Wiederhold. 2004. An information infrastructure for government regulation analysis and compliance assistance. In Proceedings of the 2004 Annual National Conference on Digital Government Research (Seattle, WA, May 24 - 26, 2004). dg.o, vol. 262. Digital Government Society of North America, 1-2. 
[52] Lee, S, R. Gandhi, D. Muthurajan, D. Yavagal, and G. Ahn. 2006. Building problem domain ontology from security requirements in regulatory documents. In Proceedings of the 2006 international Workshop on Software Engineering For Secure Systems (Shanghai, China, May 20 - 21, 2006). SESS '06. ACM, New York, NY, 43-50.

[53] Lee, S, R. A. Gandhi, and S. Wagle. 2007. Towards a Requirements-Driven Workbench for Supporting Software Certification and Accreditation. In Proceedings of the Third international Workshop on Software Engineering For Secure Systems (May 20 - 26, 2007). International Conference on Software Engineering. IEEE Computer Society, Washington, DC, 8.

[54] Li, N, T. Yu and A. I. Anton. 2003. A semantics-base approach to privacy languages. Proceedings IEEE Symposium on Security and Privacy, 2003.

[55] Lin, J, C. Lin, J. Cleland-Huang, R. Settimi, J. Amaya, G. Bedford, B. Berenbach, O. Khadra, C. Duan, and X. Zou. 2006. Poirot: A Distributed tool Supporting Enterprise-Wide Automated Traceability. In Proceedings of the 14th IEEE international Requirements Engineering Conference (September 11 - 15, 2006). RE. IEEE Computer Society, Washington, DC, 356-357.

[56] Geilson Loureiro, Paul G. Leaney, and M. Hodgson. 2004. A systems engineering framework for integrated automotive development: Regular Papers. Syst. Eng. 7(2): 153-166.

[57] Mackey, W.F. 2001. Computer Sciences Corporation The Regulatory History and Environment for Development of Telecommunications Systems in the United States, The Eleventh Annual Internation Symposium of The International Council On Systems Engineering, Melboune, Australia on July 1 - 5, 2001

[58] Massey, A. K, and A. I. Anton. 2008. A Requirements-based Comparison of Privacy Taxonomies. In Proceedings of Requirements Engineering and Law RELAW '08. pp.1-5.

[59] Massey, A. K, P. N. Otto, L. J. Hayward, and A. I. Antón. 2010. Evaluating existing security and privacy requirements for legal compliance. Requirements Engineering 15(1): 119-137.

[60] Maxwell, J. C. and A. I. Anton. 2009. Developing Production Rule Models to Aid in Acquiring Requirements from Legal Texts. In Proceedings of the 2009 17th IEEE international Requirements Engineering Conference, (August 31 - September 04, 2009). RE. IEEE Computer Society, Washington, DC, 101-110.

[61] Mitchell, S. M, C. B. Seaman. 2009. A comparison of software cost, duration, and quality for waterfall vs. iterative and incremental development: A systematic review. . 3rd International Symposium on Empirical Software Engineering and Measurement ESEM 2009. pp.511-515.

[62] Natt och Dag, J, V. Gervasi, S. Brinkkemper, and B. Regnell. 2004. Speeding up Requirements Management in a Product Software Company: Linking Customer Wishes to Product Requirements through Linguistic Engineering. In Proceedings of the 12th IEEE international Requirements Engineering Conference. (September 06 - 10, 2004). IEEE Computer Society, Washington, DC, 283-294.

[63] Natt och Dag, J, T. Thelin, and B. Regnell. 2006. An experiment on linguistic tool support for consolidation of requirements from multiple sources in market-driven product development. Empirical Software Engineering 11(1): 303-329.

[64] Otto, P. N. and A. I. Anton. 2007. Addressing Legal Requirements in Requirements Engineering. In Proceedings of the $15^{\text {th }}$ IEEE International Requirements Engineering Conference. pp. 5-14, 15-19 Oct. 2007. 
[65] Otto, P. N. and A. I. Antón. 2009. Managing Legal Texts in Requirements Engineering. Requirements Engineering: A Ten-Year Perspective, Lecture Notes in Business Information Processing 14(5): 374-393.

[66] Petersen, K, R. Feldt, M. Shahid, and M. Mattsson. 2008. Systematic Mapping Studies in Software Engineering. In Proceedings of the 12th International Conference on Evaluation and Assessment in Software Engineering (EASE), Department of Informatics, University of Bari, Italy, June 2008.

[67] Rose, D. E. and R. K. Belew. 1989. Legal information retrieval a hybrid approach. In Proceedings of the 2nd international Conference on Artificial intelligence and Law (Vancouver, British Columbia, Canada). ICAIL '89. ACM, New York, NY, 138-146.

[68] Sage, P, and C. L. Lynch. 1997. System Integration and Architecting: An Overview of Principles, Practices and Perspectives. Systems Engineering Journal 1(3): 176-227.

[69] Schweighofer, E, A. Rauber, and M. Dittenbach. 2001. Automatic text representation, classification and labeling in European law. In Proceedings of the 8th international Conference on Artificial intelligence and Law (St. Louis, Missouri, United States). ICAIL '01. ACM, New York, NY, 78-87.

[70] Schweighofer, E, W. Winiwarter, and D. Merkl. 1995. Information filtering: the computation of similarities in large corpora of legal texts. In Proceedings of the $5^{\text {th }}$ Int. Conference on Artificial Intelligence and Law (College Park, Maryland, United States, May 21 - 24, 1995). ICAIL '95. ACM, New York, NY, 119-126.

[71] Siena, A, A. Perini, A. Susi, and J. Mylopoulos. 2009. A Meta-Model for Modeling Law-Compliant Requirements. In Proceedings of the 2009 Second international Workshop on Requirements Engineering and Law (September 01 - 01, 2009). RELAW. IEEE Computer Society, Washington, DC, 45-51.

[72] Siena A, J. Mylopoulos, A. Perini, and A. Susi. 2008. From Laws to Requirements. First Int. Workshop on Requirements Engineering and Law, pp. 6-10.

[73] Smartt C. and S. Ferreira. 2010. Advancing systems engineering in support of the bid and proposal process. Systems Engineering Journal, 2010, doi: 10.1002/sys.20177

[74] Smite, D, C. Wohlin, R. Feldt, and T. Gorschek. 2008. Reporting Empirical Research in Global Software Engineering: A Classification Scheme. In Proceedings of the IEEE International Conference on Global Software 2008. ICGSE. pp.173-181, 17-20 Aug. 2008

[75] Smith, J. C. 1997. The use of lexicons in information retrieval in legal databases. In Proceedings of the 6th international Conference on Artificial intelligence and Law (Melbourne, Australia, June 30 - July 03, 1997). ICAIL '97. ACM, New York, NY, 29-38.

[76] Sommerville I. and P. Sawyer. Requirements engineering: a good practice guide. John Wiley \& Sons, 1997.

[77] Spinosa, P, G. Giardiello, M. Cherubini, S. Marchi, G. Venturi, and S. Montemagni. 2009. NLP-based metadata extraction for legal text consolidation. In Proceedings of the 12th Int. Conference on Artificial intelligence and Law (Barcelona, Spain, June 08 - 12, 2009). ICAIL '09. ACM, New York, NY, 40-49.

[78] Staples M. and M. Niazi. 2007. Experiences using systematic review guidelines. Journal of Systems and Software 80(9): 1425-1437.

[79] Svensson, R. B, M. Host and B. Regnell. 2010. Managing Quality Requirements: A Systematic Review. In Proceedings of the $36^{\text {th }}$ EUROMICRO Conference on Software Engineering and Advanced Applications. 
[80] Tashi, I. 2009. Regulatory Compliance and Information Security Assurance. In Proceedings of the International Conference on Availability, Reliability and Security. pp.670-674.

[81] Torkar, R, T. Gorschek, R. Feldt, U. Akbar Raja, and K. Kamran. 2009. Requirements traceability state-of-the-art: A systematic review and industry case study, IST Journal, in submission, 2009.

[82] The archive of proceedings of ICSE conference can be found at http://portal . acm. org/toc . cfm?id=SERIES402\&idx=SERIES402\&typ $\mathrm{e}=$ series\&coll=portal\&dl=ACM\&part=series\&WantType=Proceedings \&title $=$ ICSE\&CFID $=27744130 \&$ CFTOKEN $=48712950$

[83] The ICGSE conference information can be found at http://icgse2011. soberit.hut.fi/

[84] The information about the TEFSE workshop can be accessed at http://WwW. traceabilitycenter .org/node/474

[85] The information about the SESS workshop can be found at http://homes.dico.unimi.it/ monga/sesso9.html

[86] The information about the SEHC workshop can be found at http://www.sehc.info/

[87] The information about the WCECS conference can be found at http : //WWW. iaeng.org/WCECS2010/travel_main.html

[88] The history of the ICMLC conference can be found at http://www. icmlc.org/conf. htm

[89] The full list of all ICMLA conferences can be found at http: //www. icmla-conference.org/

[90] The full list of all ICAIL conferences publications can be found at http : //portal . acm. org/toc. cfm?id=SERIES732\&idx=SERIES732\&typ $\mathrm{e}=$ series\&coll=\&dl=ACM\&part=series\&WantType=Proceedings\&title $=$ ICAIL \&CFID $=107537019 \&$ CFTOKEN $=46439711$

[91] The full list of publications at MSR workshop at ICSE can be found at http://2011. msrconf .org/

[92] The list of all Requirements Engineering conferences, including he symposia is available here http: //Www . requirements-engineering . org

[93] The ESEJ journal can be http: //WwW. springerlink . com/content/1382-3256

[94] The full list of all REFSQ conferences can be accessed at http://www.sse.uni-due.de/refsq/2011/?page_id=40

[95] The full list of all Software Quality Journal publications can be found at http://WWW. springerlink . com/content/0963-9314

[96] The full list of publications at the IST journal can be found at http://Www.elsevier.com/wps/find/journaldescription.cws_home /525444/description\#description

[97] The full list of issues of Requirements Engineering journal can be accessed at http://WWW. springerlink. com/content/0947-3602

[98] The full list of all editions of International Workshop on Requirements Engineering and Law can be accessed at http://www. csc2. ncsu. edu/workshops/relaw/

[99] The Transactions on Software Engineering journal can be found at http : //Www . computer . org/portal/web/tse/ 
[100]Thompson A. J, J. F. Povacz and R. A. Bennett. 2009. Compliance Mapping of Industry Standards at Rockwell Collins، Technical Consistent Process Using a Requirements Database. Proceedings of 19th Annual INCOSE International Symposium.

[101]Updegrove, A. 2005. The Rise of the Meta-standard Consortium. Consortium Standards Bulletin 4(5).

[102]Valerdi R. and H. L. Davidz. 2009. Empirical research in systems engineering: challenges and opportunities of a new frontier. Systems Engineering Journal 12(2): 169-181.

[103]Vanek F, P. Jackson, and R. Grzybowski. 2008. Systems engineering metrics and applications in product development: A critical literature review and agenda for further research. Systems Engineering Journal 11(2): 107-124.

[104]Weber-Jahnke, J. H, and A. Onabajo. 2009. Finding Defects in Natural Language Confidentiality Requirements. In Proceedings of the 2009 17th IEEE international Requirements Engineering Conference, RE (August 31 - September 04, 2009). RE. IEEE Computer Society, Washington, DC, 213-222.

[105]Weber-Jahnke, J. H. and A. Onabajo. 2009. Mining and analyzing security goal models in health information systems. In Proceedings of the 2009 ICSE Workshop on Software Engineering in Health Care (May 18 - 19, 2009). International Conference on Software Engineering. IEEE Computer Society, Washington, DC, 42-52.

[106] The CSER conference can be found at http: //cser . lboro . ac . uk/

[107]The Systems Engineering Journal (SEJ) can be found at http://onlinelibrary.wiley.com/journal/10.1002/(ISSN)1520-68 58

\section{Biography}

Krzysztof Wnuk is a doctoral candidate in requirements engineering the Department of Computer Science, Lund University Sweden. His main research interests include market-driven software development, requirements engineering, decision making and empirical research methods. Prior to joining Lund University, he spent several years working in industry at various positions. He is a member of IEEE and ACM.

Brian Berenbach is a senior consultant in the requirements engineering program at Siemens Corporate Research, and is an ACM distinguished engineer. His book, Software And Systems Requirements Engineering: In Practice was published by McGraw-Hill last year, and he was recently the industrial track chair at the IEEE International Requirements Engineering Conference. 